\title{
Habilidades sociais e Coping em pacientes à espera do transplante de fígado e rim
}

\section{Social skills and Coping in patients awaiting liver and kidney transplant Habilidades sociales y Coping en pacientes que esperan un trasplante de hígado y riñón}

\author{
Larissa Beatriz Cossalter ${ }^{1}$, Michelle Angotti ${ }^{2}$, Nathália Sabaine Cippola ${ }^{2}$
}

\footnotetext{
[1] [2] [3] Centro Universitário Barão de Mauá I Título abreviado: Habilidades Sociais e Coping: levantamento de repertório | Endereço para correspondência: Centro Universitário Barão de Mauá, Rua Ramos de Azevedo, 423, Jardim Paulista, Ribeirão Preto - São Paulo, $14090-180$ I Email: larissacossalter@hotmail.com I 10.18761/PAC.2016.044
}

Resumo: Coping é uma resposta cujo objetivo é aumentar, criar ou manter a percepção de controle pessoal frente a uma situação de estresse e um bom repertório social é uma das maneiras de aumentar reforçadores, pois o sujeito é capaz de resolver problemas imediatos e diminui os futuros, respeitando a si e o outro. A presente pesquisa teve como objetivo avaliar o repertório de habilidades sociais e o Coping de indivíduos que se encontravam na lista de espera do transplante de fígado e rim. Participaram quarenta indivíduos de um hospital público, com idades entre 22 e 68 anos que responderam a dois inventários que avaliavam essas duas variáveis. Os resultados mostraram correlação positiva e baixa entre os dois repertórios. Muitos dos participantes possuíam repertório social ruim, com indicação para treino de habilidades sociais. $\mathrm{O}$ aumento do repertório social poderia auxiliar no enfrentamento de doenças crônicas, facilitando o engajamento dos pacientes no tratamento.

Palavras-chave: coping, habilidades sociais, transplante de fígado, transplante renal.

Abstract: Coping é uma resposta cujo objetivo é aumentar, criar ou manter a percepção de controle pessoal frente a uma situação de estresse e um bom repertório social é uma das maneiras de aumentar reforçadores, pois o sujeito é capaz de resolver problemas imediatos e diminui os futuros, respeitando a si e o outro. A presente pesquisa teve como objetivo avaliar o repertório de habilidades sociais e o Coping de indivíduos que se encontravam na lista de espera do transplante de fígado e rim. Participaram quarenta indivíduos de um hospital público, com idades entre 22 e 68 anos que responderam a dois inventários que avaliavam essas duas variáveis. Os resultados mostraram correlação positiva e baixa entre os dois repertórios. Muitos dos participantes possuíam repertório social ruim, com indicação para treino de habilidades sociais. O aumento do repertório social poderia auxiliar no enfrentamento de doenças crônicas, facilitando o engajamento dos pacientes no tratamento.

Keywords: coping, social skills, liver transplant, kidney transplant. 
Resumen: El afrontamiento es una respuesta dirigida a aumentar, crear o mantener la percepción de control personal frente a una situación de estrés y las habilidades sociales son una de las formas de aumentar los reforzadores, porque el sujeto es capaz de resolver problemas inmediatos y disminuye problemas futuros, respetando a sí mismo y al otro. El objetivo de esta investigación fue valorar el conjunto de habilidades sociales y lo Coping de las personas que estaban en la lista de espera de trasplante de hígado y riñón. Cuarenta individuos de un hospital público, de entre 22 y 68 años, contestaron a dos encuestas que evaluaron estas dos variables. Los resultados mostraron correlación positiva y baja entre los dos contextos. Muchos de los participantes tenían malas habilidades sociales, direccionando a un entrenamiento de las mismas. El aumento de dichas habilidades podría ayudar a afrontar a las enfermedades crónicas, lo que facilita la participación de los pacientes en el tratamiento.

Palabras-clave: afrontamiento, habilidades sociales, trasplante de hígado, trasplante de riñón. 
Durante a vida, os indivíduos experimentam situações de estresse que geralmente causam tensão emocional e física, levando os sujeitos a lidarem com essas situações de maneiras diferentes. Neste momento os indivíduos devem emitir algum comportamento, seja verbal ou não-verbal, para reduzir o estresse. Esse comportamento é o que está envolvido nos processos de Coping, termo do original em inglês, que tem sido traduzido para o português por processo de enfrentamento ou enfrentamento (Ramos, Enumo \& Paula, 2015).

Lazarus e Folkman (1984) definiram Coping como um conjunto de esforços, cognitivos e comportamentais, utilizado pelos indivíduos, com o objetivo de criar, aumentar ou manter a percepção de controle pessoal frente a demandas específicas, internas ou externas, que surgem em situações de stress e são avaliadas como sobrecarregando ou excedendo seus recursos pessoais. Dentro dessa proposta, procuravam entender o Coping como um processo resultante da relação entre o indivíduo e o ambiente, buscando seus determinantes situacionais e cognitivos.

Os mecanismos de Coping podem ser divididos de duas formas: centrados na emoção ou no problema. O centrado na emoção pode reduzir a sensação de desconforto emocional, e é utilizado com maior frequência em situações percebidas como imutáveis. Quando centrado no problema visa mudanças diretas no ambiente, sendo utilizado com maior frequência quando a condição é avaliada como passível de ser modificada. Ambos se influenciam mutuamente e podem ser utilizados pelo mesmo indivíduo, cada um apresentando vantagens e desvantagens, dependendo da situação e do momento de utilização (Lazarus \& Folkman, 1984). Em procedimentos da saúde, a identificação de estressores, bem como do Coping utilizado pelos pacientes para "minimizar" o impacto do estresse sobre o organismo, são importantes preditores da qualidade de vida antes e depois de procedimentos médicos (Ravagnani, Domingos \& Miyazaki, 2007).

Ao se buscar as estratégias metodológicas utilizadas na literatura em relação às medidas de Coping observa-se que há poucos instrumentos construídos, inclusive no Brasil. Moss e Billings (1982) foram os primeiros a classificarem o Coping em três diferentes áreas, de acordo com a preferência do sujeito. O inventário de estratégias de Coping de Folkman e Lazarus (1985) possui 66 itens que englobam pensamentos e ações que as pessoas utilizam para lidar com demandas internas ou externas. Stone e Neale (1984) desenvolveram uma lista com 55 itens que englobavam a descrição de como os sujeitos haviam lidado com a situação estressante. McCrae (1984) desenvolveu um instrumento de 118 itens distribuídos em 28 categorias, em um estudo com o objetivo de verificar se as estratégias de Coping eram devidas a variáveis de personalidade. Savóia e Mejias (2000) traduziram e validaram o Inventário de Estratégias de Coping de Folkman e Lazarus (1985).

Outro instrumento, agora mais específico para a medida de Coping relacionado à problemas da saúde, foi desenvolvido por Endler, Summerfeldt e Parker (1980) e traduzido por Ruivo (1999), com o objetivo de identificar o nível de stress, coping e qualidade de vida de 184 indivíduos sujeitos a transplante renal em um hospital de Portugal. O instrumento se mostrou eficaz na captação de dados referente ao Coping e a área da saúde, identificando níveis médios de stress, coping e qualidade de vida dos participantes.

No caso do Coping no contexto da doença, vários estudos tentam conhecer as estratégias utilizadas pelos pacientes e familiares. Hymovich e Hagopian (1992) listaram as seguintes estratégias centradas no problema: a) procurar informação sobre sua condição; b) procurar habilitar-se para o autocuidado; c) buscar e usar recursos em serviços de saúde ou redes de suporte social; d) auto monitorização de sinais e sintomas; e) aderir à terapia indo às consultas, fazendo o uso correto da medicação e controlando os comportamentos de risco para a doença; f) ajustar-se ao estilo de vida familiar; g) organizar e distribuir o tempo para realizar atividades referentes à saúde, ao desenvolvimento social e ao lazer; $h$ ) modificar os papéis sociais e o ambiente de acordo com a necessidade.

Quanto às estratégias de Coping relacionadas à emoção Hymovich e Hagopian (1992) citam: a) sentimentos de incerteza, ansiedade, apreensão frente ao diagnóstico médico, aos procedimentos diagnósticos e tratamento; b) pensar sobre o significado da doença e o provável impacto dessa em seu cotidiano; c) atribuir causas à doença e possíveis 
resultados como forma de ter controle sobre à situação; d) ter pensamentos irreais como pensar que pode controlar sua condição de saúde, quando isto não é possível; e) fazer comparações com situações piores; f) apresentar sentimento de ambiguidade, quando tenta passar uma imagem falsa para os outros com o objetivo de ser aceito; g) manter a esperança de que o amanhã pode ser melhor e h) usar mecanismos de defesa.

No caso de doenças crônicas como a insuficiência hepática ou renal, o Coping tem papel mediador entre sujeito, saúde e doença. A presença de uma doença crônica leva à necessidade de adaptação, tanto por parte do paciente quanto de seus familiares. Sentimentos de abandono, desesperança, medo da morte, baixa autoestima, ansiedade e depressão, por exemplo, manifestam-se frequentemente nos pacientes. É preciso desenvolver estratégias para enfrentar sintomas ou limitações, para adaptar-se a sua nova realidade: seu papel na sociedade, vida profissional, financeira, tratamento e internações (Miyazaki, Domingos, Valério, Souza \& Silva, 2005).

Assim, as estratégias de Coping se tornam fundamentais no enfrentamento da doença e nos procedimentos médicos exigidos. Pacientes com doença hepática ou renal crônica, por exemplo, podem ter como único recurso terapêutico o transplante. Neste caso, a doença pode ser percebida pelo indivíduo como um importante estressor, uma vez que acarreta mudanças significativas no funcionamento e no estilo de vida do paciente e de toda a família (Domingos, Lipp \& Miyazaki, 2012).

Compreender aspectos associados ao Coping utilizados por pacientes submetidos a um transplante pode auxiliar no desenvolvimento de programas de intervenção adequados às necessidades desses pacientes (Ravagnani et al., 2007). No estudo de Telles-Correia, Mega, Barbosa, Barroso e Monteiro (2008), por exemplo, se demonstrou que o Coping e a adesão são instáveis ao longo da evolução clínica do indivíduo transplantado, desde o período de pré-transplante, aos períodos de pós-transplante imediato e pós-transplante tardio.

Lazarus e Folkman (1984) consideram que o baixo repertório de Coping pode prejudicar um paciente por impedi-lo de emitir, em alguns casos, os comportamentos adaptativos frente à doença, por exemplo, na adesão ao tratamento. Esses pacien- tes podem ser negligentes quanto a medicação, ida às consultas, cumprimento de dieta ou exercícios prescritos, entre outros.

Esses comportamentos entendidos como Coping dependem do repertório individual e experiências tipicamente reforçadas. Observa-se como influência recursos culturais, materiais, valores, crenças, apoio social e o repertório socialmente habilidoso do indivíduo (Ravagnani et al., 2007). Portanto, há maior probabilidade do indivíduo lidar com situações de conflito que envolvem estimulação aversiva ampliando-se o repertório social.

Assim, o desenvolvimento do Coping é tão importante quanto o desenvolvimento das habilidades sociais que garantem interações sociais bem-sucedidas, afinal, sucesso pessoal e social, são em grande parte, determinados pelas habilidades do indivíduo em iniciar e manter interações sociais saudáveis, gerando consequências reforçadoras para si (Caballo, 2006). Dessa forma, a percepção da pessoa sobre a sua competência social afeta suas emoções, pensamentos e outros fatores que influenciarão em seu comportamento (Pinto \& Barham, 2014).

Caballo (2006) considera que o comportamento socialmente hábil é aquele conjunto de comportamentos emitidos por um indivíduo em um contexto interpessoal específico, expressando sentimentos, atitudes, desejos, opiniões ou direitos, de modo adequado à aquela situação, respeitando os demais e, geralmente, resolvendo os problemas imediatos da situação ao mesmo tempo em que minimiza a probabilidade de problemas futuros.

As classes de habilidades, segundo Del Prette e Del Prette (2010), são relações funcionais entre respostas de duas ou mais pessoas em interação, em que as respostas de uma pessoa podem funcionar como antecedente ou consequente, e como uma premissa básica para o princípio do behaviorismo radical, todo comportamento é produto de três níveis de variação e seleção: filogenética, ontogenética e cultural. Para a construção de um repertório de habilidades sociais estes princípios também se aplicam. A seleção filogenética forneceu aos seres humanos características anatômicas, fisiológicas e comportamentais importantes para a sobrevivência social, como musculatura vocal para emissão do comportamento verbal, expressões faciais que 
facilitam as interações sociais, tendência humana à sociabilização, entre outros.

O fator ontogenético foi amplamente estudado pela literatura e traz as habilidades sociais como um produto da aprendizagem alterado ao longo da vida do sujeito devido a processos de variação e seleção produzidos pelas contingências ambientais. Essa seleção pode ocorrer através das contingências naturais em que o indivíduo está inserido ou por contingências estruturadas, através do treino de habilidades sociais, em programas terapêuticos ou educacionais. A seleção cultural também pode ser aplicada às habilidades sociais, já que todas essas habilidades humanas e sociais favoreceram o surgimento da cultura e das práticas culturais. "A eficácia ou ineficácia de certas práticas culturais de relações sociais podem determinar se serão ou não adotados pelos membros do grupo e, portanto, selecionados por esse grupo" (Del Prette \& Del Prette, 2010, p. 09).

Del Prette e Del Prette (2001) organizam essas habilidades em 1) habilidades sociais de comunicação: fazer e responder a perguntas; gratificar e elogiar; pedir e dar feedback nas relações sociais; iniciar, manter e encerrar conversação; 2) habilidades sociais de civilidade: dizer por favor; agradecer; apresentar-se; cumprimentar; despedir-se; 3) habilidades sociais assertivas de enfrentamento: manifestar opinião, concordar, discordar; fazer, aceitar e recusar pedidos; desculpar-se e admitir falhas; estabelecer relacionamento afetivo/sexual; encerrar relacionamento; expressar raiva e pedir mudança de comportamento; interagir com autoridades; lidar com críticas; 4) habilidades sociais empáticas: parafrasear, refletir sentimentos e expressar apoio; 5) habilidades sociais de trabalho: coordenar grupo; falar em público; resolver problemas, tomar decisões e mediar conflitos; habilidades sociais educativas; e 6) habilidades sociais de expressão de sentimento positivo: fazer amizade; expressar a solidariedade e cultivar o amor.

Não há uma maneira correta que todos os indivíduos devem se comportar, porém, é possível que ocorram falhas, durante o processo de aprendizagem, resultando em déficits relevantes de habilidades sociais (Pinto \& Barham, 2014). Del Prette e Del Prette (2005) investigaram os possíveis fatores pessoais e ambientais associados a esses déficits, como: falta de conhecimento; restrição de oportunidade e modelos; falhas de reforçamento; ausência de feedback; excesso de ansiedade interpessoal; dificuldades de discriminação e processamento e problemas de comportamento.

Apesar de haver uma descrição geral de habilidades sociais a serem foco de intervenções e de pesquisa, populações específicas têm necessidades interpessoais próprias de modo a garantir uma intervenção mais específica e com maior probabilidade de sucesso (Bolsoni-Silva \& Carrara, 2010). Caballo (2006) afirma, por exemplo, que habilidade social deve ser considerada dentro de um contexto cultural determinado, no qual os padrões de comunicação variam de forma ampla entre culturas e dentro de uma mesma cultura, dependendo de fatores como idade, sexo, classe social e educação. Portanto, para que um comportamento possa ser considerado socialmente competente deve-se levar em conta o contexto no qual se insere, visto que a maior parte do comportamento social é dirigida para um objetivo.

No caso de paciente com doenças crônicas Simmons, Marine e Simmons (1987) constataram que pacientes à espera do transplante afastam-se socialmente de pessoas que antes eram fontes reforçadoras, pois diminuem o número de interações socias, passando a pertencer a um grupo de pessoas que dependem de outras, diminuem a exposição a novas contingências, diminuem atividade profissional e de lazer e com isso o repertório comportamental fica mais restrito. Ou seja, os procedimentos e cuidados constantes com a saúde restringem as interações que antes ocorriam com maior frequência e isso dificulta o desenvolvimento de repertórios sociais.

Considerando o contexto da saúde, e mais especificamente as doenças crônicas que exigem transplante, entende-se como importante o estudo do desenvolvimento do Coping e a observação do repertório de habilidades sociais no sentido de promover interações sociais bem-sucedidas e melhorias no engajamento do tratamento, já que as necessidades desses pacientes vem despertando o interesse de especialistas nesta área e multiplicando as pesquisas sobre o tema em diferentes contextos (Bandeira, Costa, Del Prette, Del Prette \& GerkCarneiro, 2000). Além disso, o reconhecimento da relevância dessas habilidades vem contribuindo 
para investimentos a fim de aprimorar as habilidades com diferentes populações e contextos (Pinto \& Barham, 2014).

Acredita-se que quanto mais socialmente habilidoso o indivíduo for, maior a probabilidade de obter reforçadores e, por consequência, ampliar repertório comportamental, favorecendo lidar com situações de conflito que claramente envolvem estimulação aversiva, como em situações de estresse diante dos transplantes. Dessa forma, o objetivo desta pesquisa foi avaliar o repertório de Coping e habilidades sociais dos indivíduos que estavam na lista para o transplante de fígado e renal.

\section{Método}

\section{Participantes}

Participaram da pesquisa 40 indivíduos, 20 que estavam na lista de espera do transplante de fígado e 20 que estavam na lista de espera do transplante renal. As idades variaram entre 22 e 68 anos (média de 51 anos), sendo 26 do sexo masculino e 14 do sexo feminino. Foram inclusos nessa pesquisa sujeitos que estavam na lista de espera do transplante de fígado e renal no dia da aplicação dos instrumentos e que aguardavam consulta médica ou hemodiálise, independente do tempo de espera na lista. Foi perguntado aos indivíduos se os mesmos eram alfabetizados e participaram desta os que afirmaram ser. A coleta teve início mediante assinatura do Termo de Consentimento Livre e Esclarecido.

\section{Local}

A pesquisa foi realizada no Ambulatório de Transplante de Fígado e Nefro Pré-transplante e na Unidade de Hemodiálise do Hospital das Clínicas da Faculdade de Medicina de Ribeirão Preto da Universidade de São Paulo (HCFMRP-USP). As pesquisadoras abordaram os participantes nos corredores do ambulatório e na sala de espera da Unidade de Hemodiálise. Em ambos os locais, haviam cadeiras enfileiradas e posicionadas uma ao lado da outra. As pesquisadoras tiveram o cuidado para que o sigilo dos participantes fosse mantido e para que outros pacientes não observassem as respostas dos participantes.

\section{Instrumentos e Procedimentos}

A coleta teve início mediante assinatura do Termo de Consentimento Livre e Esclarecido. As instruções para a realização dos testes foram seguidas conforme orientado em cada instrumento. Foi fornecida uma folha de resposta acoplada a uma estrutura de apoio (prancheta) e caneta para responder. Metade dos participantes responderam ao IHS primeiro e depois a Escala de Coping. O restante teve a ordem de aplicação invertida. As pesquisadoras leram para cada participante as instruções sugeridas nos instrumentos e se certificaram que todos os participantes haviam entendido o que deveria ser feito, deixando com que os mesmos respondessem aos questionários individualmente. Neste momento as pesquisadoras se afastavam dos participantes em uma distância em que fosse possível observar se estavam preenchendo a folha de resposta corretamente ou não.

Foram utilizados os instrumentos: 1) Escala de Coping sobre problemas de Saúde (Ruivo, 1999) e 2) Inventário de Habilidades Sociais (IHS - Del Prette, 2001). Ambos os instrumentos continham apenas questões fechadas.

\section{1) Escala de Coping sobre problemas de} Saúde (Ruivo, 1999): A escala identifica quatro dimensões básicas de Coping, como resposta aos problemas de saúde, são elas: Distração, Paliativo, Instrumental e Emocional/ Preocupação. A escala consiste em 32 afirmações, colocadas aos indivíduos, que correspondem a diferentes formas de reação perante um problema de saúde. As respostas pretendidas têm relação com a frequência com que utilizam essas atividades no seu dia a dia. Os 32 itens são avaliados em uma escala de 1 a 5 , que representam: 1- nunca; 2 - raramente; 3 - algumas vezes; 4- quase sempre e 5- sempre. A contagem varia entre 32 (menor repertório de enfrentamento) e 160 (maior repertório de enfrentamento).

2) Inventário de Habilidades Sociais (IHS Del Prette, 2001): é um instrumento de autorelato que avalia o repertório de habilidades sociais com base na estimativa que o respondente faz sobre a frequência com que reage da forma indicada em cada item. As respostas do IHS- 
Del-Prette consistiam em 42 itens distribuídos em 5 fatores: fator 1- Enfrentamento com risco; fator 2- Autoafirmação na expressão; fator 3- Conversação e desenvoltura social; fator 4Autoexposição a desconhecidos ou a situações novas; fator 5- Autocontrole da agressividade em situações aversivas. A escala era do tipo Likert, de 5 pontos, variando de nunca ou raramente a sempre ou quase sempre.

\section{Resultados}

A Figura 1 apresenta o escore total dos 40 participantes na Escala de Coping (somando os 4 fatores) e no Inventário de Habilidades Sociais. É possível observar que há um padrão mantido pela maioria dos participantes, em que resultados maiores na Escala de Coping são seguidos de escores maiores no Inventário de Habilidades Sociais.

Para aferir o grau de associação entre os escores totais das escalas de Coping e do IHS, foi estimado o Coeficiente de Correlação de Pearson. Os escores obtidos nas variáveis de Coping e de Habilidades Sociais apresentaram correlação fraca $(r=0,21 ; p$ $=0,53)$. Com a medida positiva imperfeita nota-se que a diagramação do gráfico não é ponto a ponto, mas a tendência está presente e o padrão é entre os escores em Coping e IHS para a maioria dos participantes.

\section{Figura 1}

Observa-se que 17 participantes $(1,2,3,5,6,14,17$, $18,19,20,25,27,29,32,34,35,40)$ tiveram escore total entre 03 e 20 no IHS, classificado como um desempenho ruim, com indicação para treinamento em habilidades sociais, e resultado entre 96 e 147 pontos na Escala de Coping.

Outros 3 participantes $(26,33,38)$ apresentaram escore total no IHS de 50 pontos (indicativo de repertório médio de HS) e pontuação total na Escala de Coping de 111 a 131. No caso de 7 participantes $(4,10,12,15,28,31,36)$ o escore total do IHS foi entre 30 e 45 (indicativo de bom repertório de HS - abaixo da mediana) e pontuação total de 115 a 145 na Escala de Coping.

Observa-se também que 4 participantes $(7,13$, $30,37)$ apresentaram escore total de 60 a 70 no IHS (indicativo de bom repertório de HS - acima de média) e resultado entre 105 e 137 pontos na Escala de Coping. Outros 9 participantes $(8,9,11,16,21$, $22,23,24,39)$ tiveram escore total entre 80 e 95 no IHS (indicativo de repertório bastante elaborado) e pontuação total na Escala de Coping de 119 e 137.

A Figura 2 apresenta a classificação do repertório de habilidades sociais dos participantes candidatos ao transplante de rim e fígado, segundo o Inventário de Habilidades Sociais.

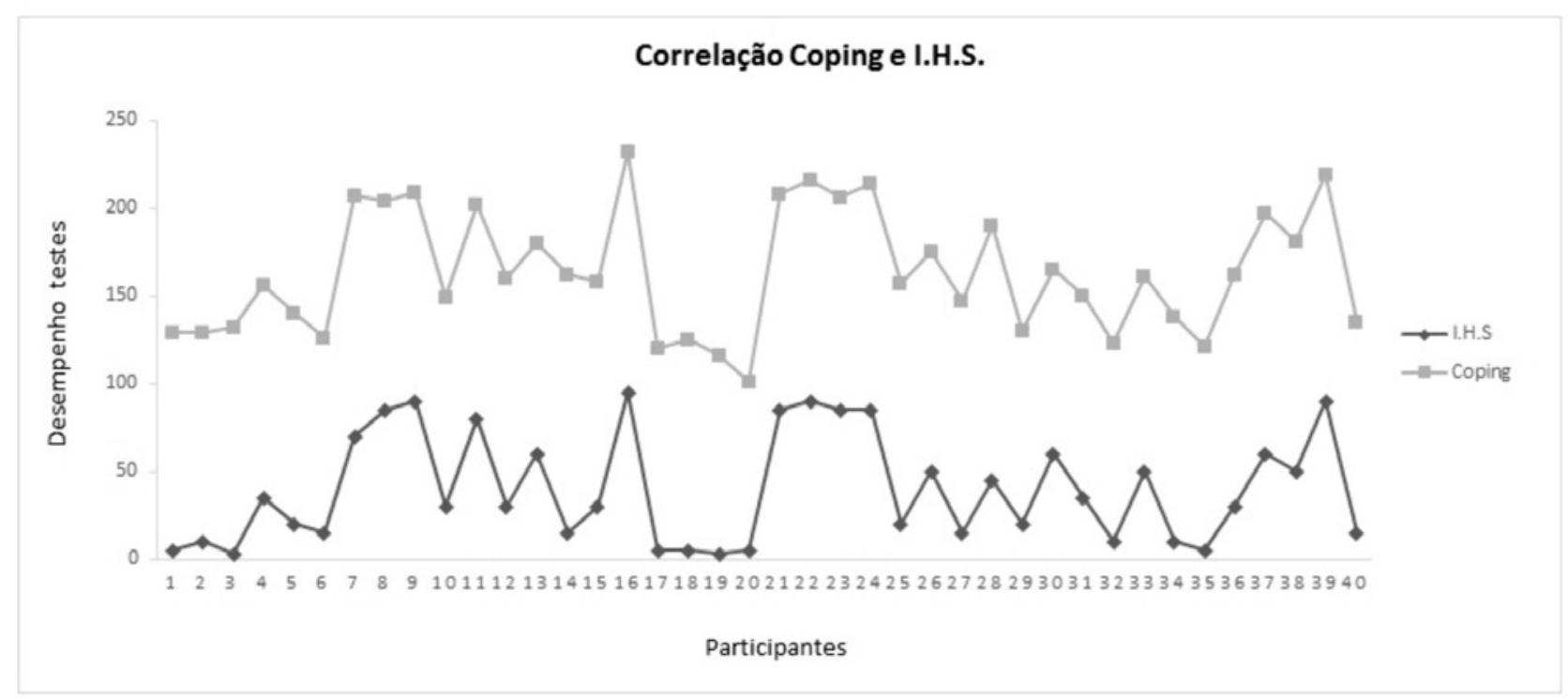

Figura 1. Desempenho dos participantes conforme o escore total na Escala de Coping e no IHS. 


\section{Figura 2}

Foi possível verificar que os pacientes à espera de um transplante renal tiveram desempenho superior quanto ao repertório de habilidades sociais relativamente aos pacientes à espera de um transplante de fígado. Menos pacientes à espera de um transplante renal tiveram desempenho compatível com a indicação para o Treinamento em Habilidades Sociais se comparados aos pacientes à espera de um transplante de fígado.

Verificou-se que 6 participantes da lista de espera para transplante de rim e 3 da lista de espera do transplante de fígado obtiveram repertório bastante elaborado no IHS. O desempenho denominado bom repertório de IHS (acima da mediana) foi obtido por 2 participantes da lista de espera para transplante de rim e por 2 da lista de espera do transplante de fígado.
No que se refere ao bom repertório (abaixo da média) no IHS, apresentaram essa classificação 4 participantes da lista de espera para transplante de rim e 3 participantes da lista de espera para transplante de fígado. Quanto ao desempenho de repertório médio foi apresentado por 2 participantes da lista de espera do transplante de rim e apenas 1 participante da lista de espera do transplante de fígado.

Verifica-se que 6 participantes da lista de espera do transplante de rim e 11 participantes da lista de espera do transplante de fígado obtiveram desempenho ruim, o que indica necessidade de treinamento em HS.

Foi calculada a média dos escores dos participantes em cada fator do IHS, que está apresentada na Figura 3.

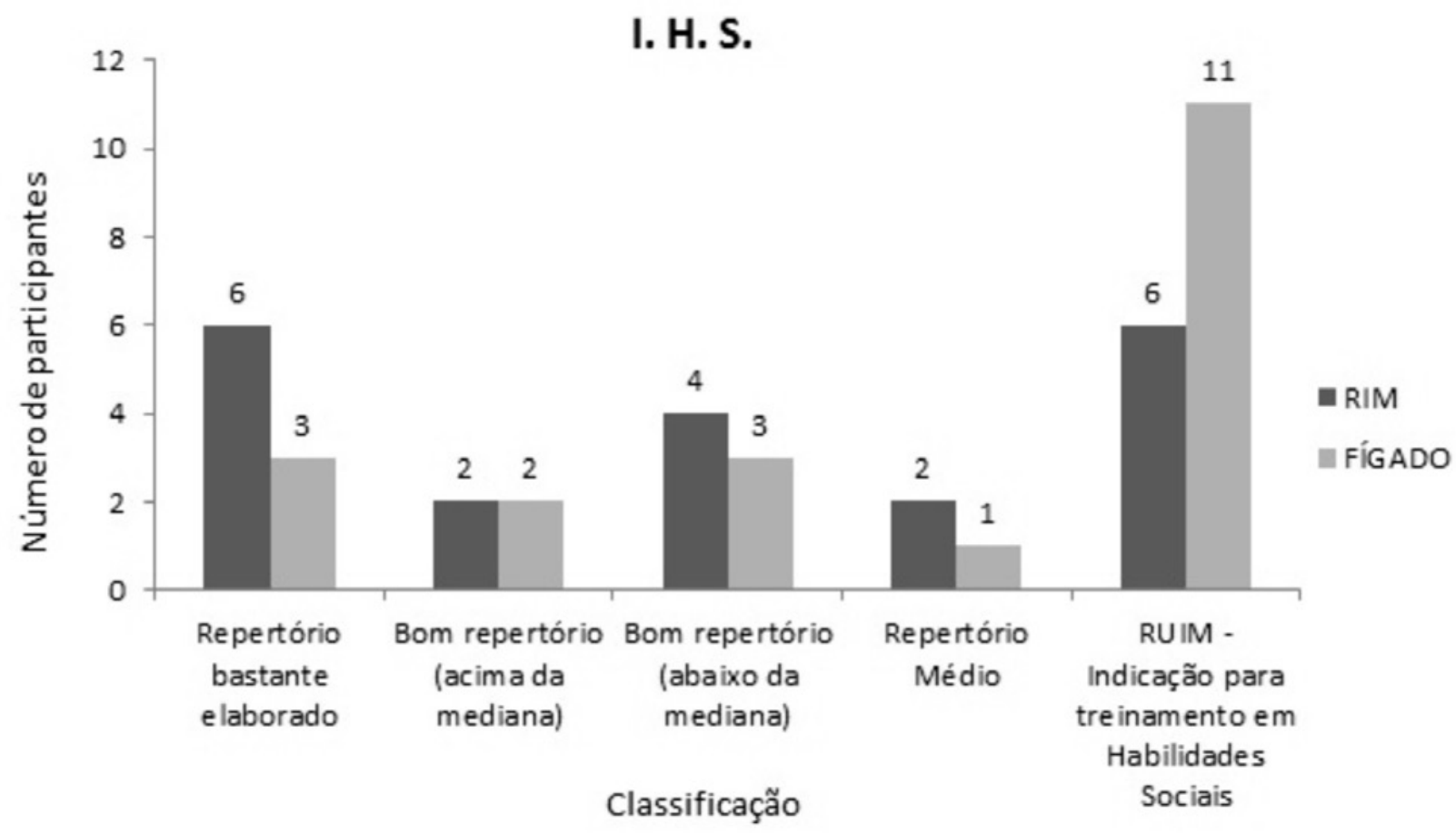

Figura 2. Número de participantes em relação ao desempenho no IHS dos candidatos à espera do transplante renal e de fígado. 


\section{Figura 3}

Verificou-se que a maior média $(70,325)$ foi a do fator 3 (Conversação e desenvoltura social), retratando que os participantes têm capacidade de lidar com situações sociais neutras de aproximação (em termos de afeto positivo ou negativo), com risco mínimo de reação indesejável, demandando principalmente "traquejo social" na conversação. Um alto escore nesse fator supõe bom conhecimento das normas de relacionamento cotidiano para o desempenho de habilidades. Seguido pelo fator 2 (Autoafirmação na expressão) com média de 69,125, demonstrando que os participantes têm habilidades para lidar com demandas de afeto positivo e de afirmação da autoestima.

A terceira maior média foi a do fator 1 (Enfrentamento com risco), sendo esta 50,575, o que indica a capacidade dos participantes de lidar com situações interpessoais que demandam a afir- mação e defesa de direitos e autoestima, com risco potencial de reação indesejável por parte do interlocutor (possibilidade de rejeição, de réplica ou de oposição).

No que diz respeito ao fator 4 (Autoexposição a desconhecidos ou a situações novas), este possui média de 47,333, o que denota estar próxima a dos outros fatores do IHS, portanto, demonstra que os participantes possuem a capacidade de abordar pessoas desconhecidas. O fator com menor média $(30,175)$ foi o fator 5 (Autocontrole da agressividade em situações aversivas), constatando que os participantes têm uma capacidade deficitária de reagir a estimulações aversivas do interlocutor com razoável controle da raiva e da agressividade.

A Figura 4 apresenta a média do desempenho de cada fator avaliado na Escala de Coping, divididos entre os candidatos à espera do transplante de rim e de fígado.

\section{FATORES DO IHS}

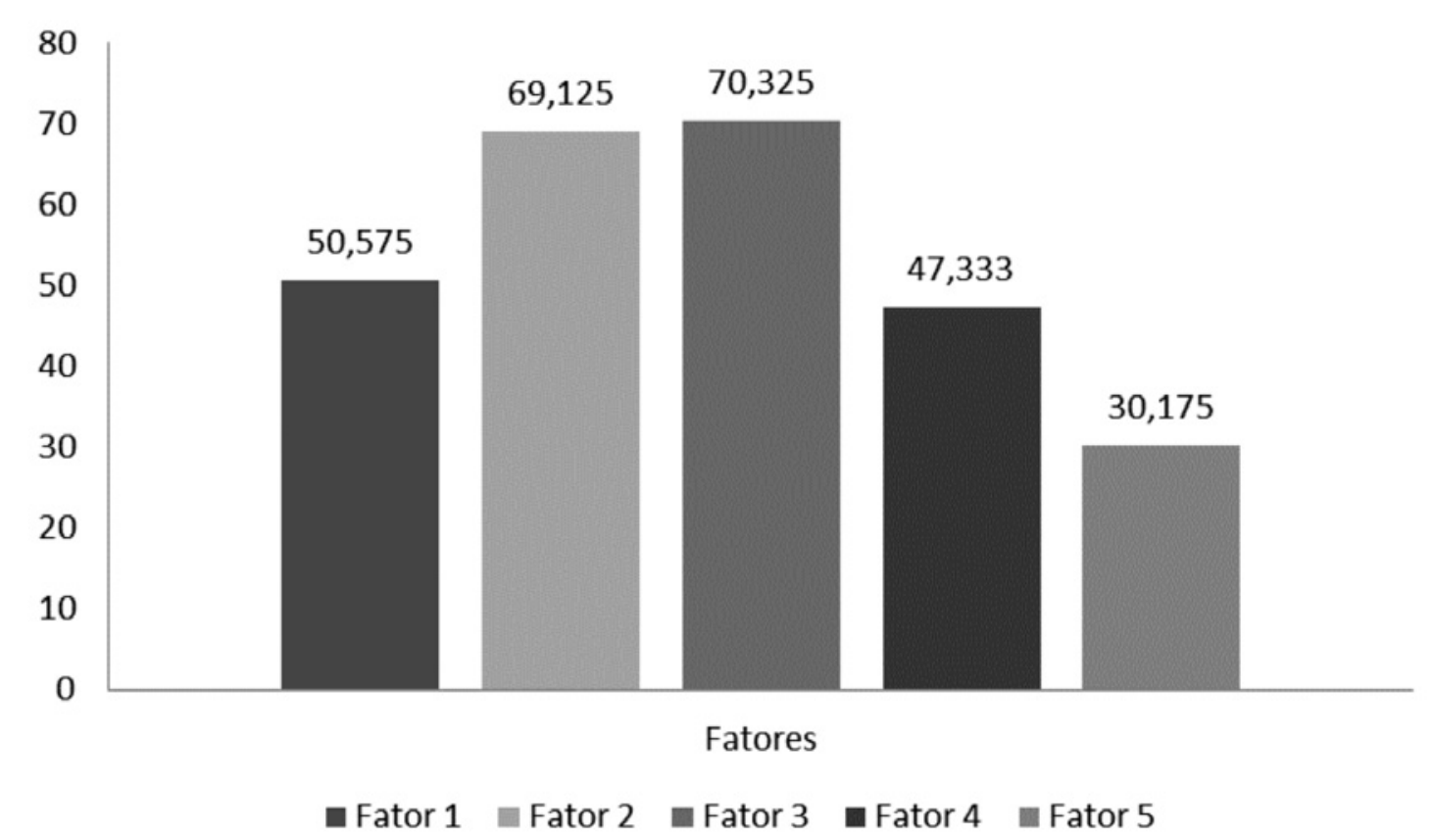

Figura 3. Média de todos os participantes no IHS divididas nos 5 fatores avaliados. 


\section{Figura 4}

Quanto as médias obtidas na Escala do Coping, o fator com maior média foi o Instrumental, o que demonstra que os participantes estão comprometidos com as orientações médicas e com sua saúde. Em seguida, vem o Fator Distração, indicando que se envolvem em atividades consideradas agradáveis que não tenham relação com o problema de saúde.

Observando a média do Fator Paliativo, constata-se que os participantes emitem comporta- mentos de autocuidado. Com menor média vem o Fator Emocional/Preocupação, porém, uma média elevada neste fator denota que os indivíduos não têm reações emocionais adequadas relacionadas ao problema de saúde.

Pôde-se verificar também que as médias dos participantes da lista de espera do transplante de fígado são inferiores aos dos participantes da lista de espera do transplante renal em todos os fatores do Coping, exceto no Fator Emocional/Preocupação onde a média é igual.

\section{Escala de Coping}

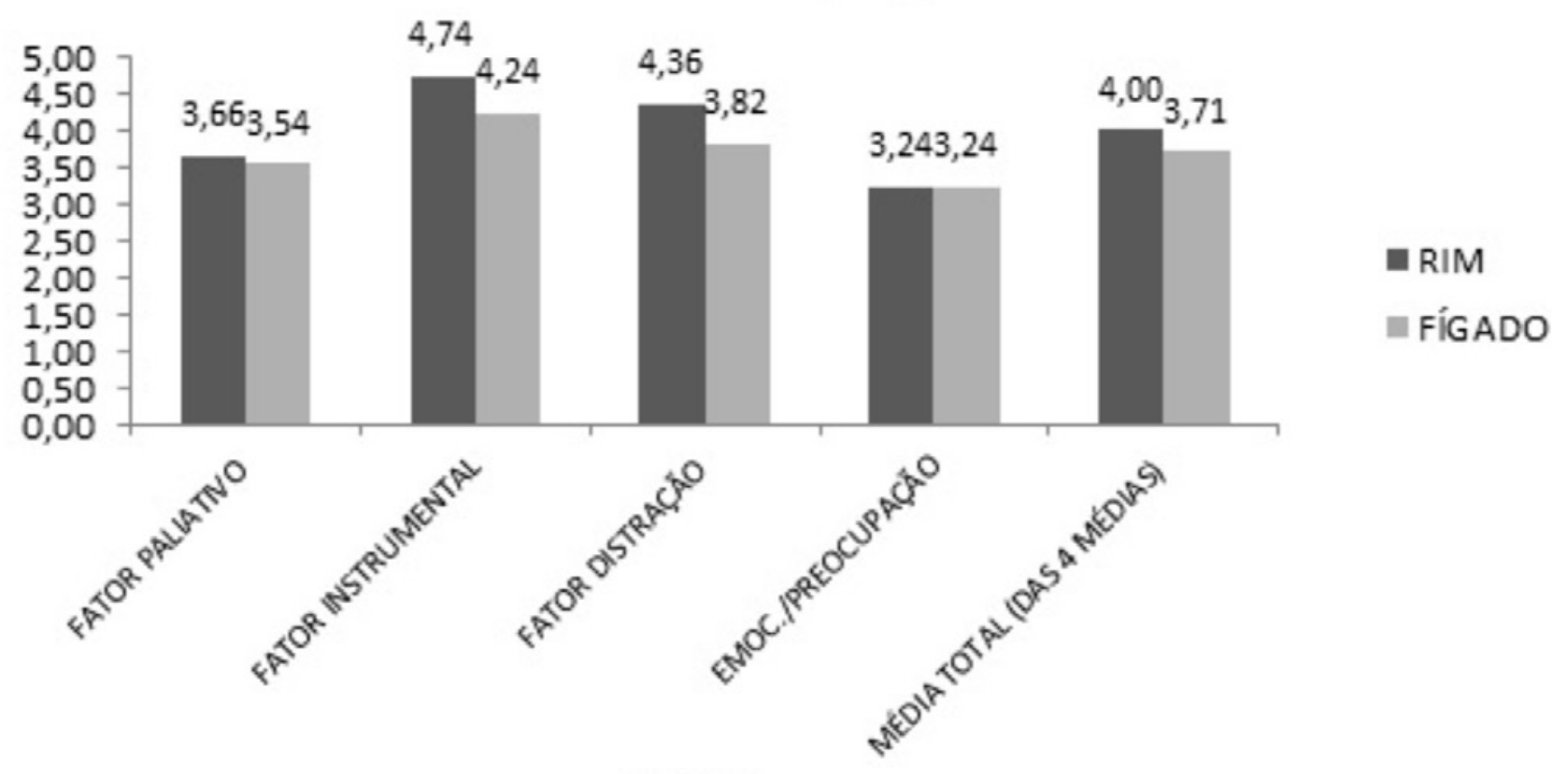

Fatores

Figura 4. Média do desempenho de cada fator na escala de Coping e a média total

\section{Tabela 1}

Para comparar o desempenho dos participantes à espera de Fígado e Rim nas escalas de Coping e de IHS foi utilizado o escore total no teste $U$ de Mann-Whitney. Optou-se por esta técnica não paramétrica pelo fato das variáveis não atenderem aos pressupostos de normalidade e homogeneidade das variâncias, testados pelos testes de Shapiro-Wilk e de Levene, respectivamente.
A Tabela 1 mostra o resultado do Teste $U$ de Mann-Whitney, que indicou que o escore obtido no Inventário de Habilidades Sociais não foi significativamente diferente entre os grupos Fígado ( $\mathrm{Mdn}$ $=17,5)$ e $\operatorname{Rim}(M d n=47,5), U=133, p=0,07 . \mathrm{Em}$ relação ao escore obtido na Escala de Coping, os pacientes à espera de rim $(\mathrm{Mdn}=127)$ tiveram pontuação significativamente maior que os pacientes à espera de Fígado $(\mathrm{Mdn}=119), \mathrm{U}=109,5, \mathrm{p}=0,01$. 
Tabela 1. Apresentação da média dos resultados dos participantes na Escala de Coping e no IHS divididas de acordo com o tipo de transplante.

\begin{tabular}{|c|c|c|c|c|c|c|}
\hline & & $\mathrm{N}$ & Mediana & Rank Médio & Soma dos Ranks & $U(p)$ \\
\hline \multirow{2}{*}{ IHS } & Grupo Fígado & 20 & 17,5 & 17,2 & 343 & \multirow{2}{*}{$133(0,07)$} \\
\hline & Grupo Rim & 20 & 47,5 & 23,9 & 477 & \\
\hline \multirow{2}{*}{ Coping* } & Grupo Fígado & 20 & 119 & 16,0 & 319,5 & \multirow{2}{*}{$109,5(0,01)$} \\
\hline & Grupo Rim & 20 & 127 & 25,0 & 500,5 & \\
\hline
\end{tabular}

\section{Discussão}

A pesquisa tinha como objetivo avaliar o repertório de Coping e Habilidades sociais em indivíduos a espera do transplante de fígado e rim e a possível correlação entre essas variáveis. A identificação de aspectos que interferem no comportamento de enfrentamento e das estratégias mais utilizadas pelos pacientes à espera de um transplante para minimizar o impacto do estresse sobre o organismo, são importantes preditores da qualidade de vida de pacientes à espera de um transplante. Além disso, podem fornecer importantes subsídios para o planejamento de programas preventivos (Ravagnani et al., 2007).

De uma maneira geral, os participantes que apresentaram maior repertório de enfrentamento tinham mais recursos sociais e os que apresentaram baixo Coping possuíam indicação para treinamento em habilidades sociais. É importante destacar aqui a ideia que um relacionamento correlacional não pode ser considerado como causalidade. Assim, o baixo repertório de habilidades sociais não causa queda do repertório de Coping. Ele é apenas uma variável que pode interferir neste conjunto de comportamentos caracterizado como Coping.

Deve-se destacar também os resultados de alguns participantes que não tiveram o mesmo padrão apresentado pela maioria. Embora não tenha sido o objetivo da pesquisa, pode-se especular que o tempo de doença, o tempo de espera na lista, a idade do paciente, a variabilidade de recursos de apoio podem ser variáveis que alteram o repertório de Coping e habilidades sociais. Ravagnani et al., (2007) coloca que estratégias de Coping utilizadas dependem dos recursos culturais, materiais, valores, crenças, habilidades sociais e apoio social de cada indivíduo. Nesta pesquisa não houve um detalhamento das variáveis que poderiam ocasionar tal diferença e sugere-se que futuras pesquisas se atentem para fatores individuais também.

A partir dos resultados obtidos na presente pesquisa, em que se observa uma fraca, mas positiva correlação do repertório de habilidades sociais e Coping, propõe-se o treino de habilidades sociais como recurso para melhorar o repertório de enfrentamento de pacientes à espera do transplante. A intervenção para o ensino de um repertório socialmente habilidoso nomeia-se treino de habilidades sociais. Em seu conjunto, essas técnicas visam a modificar componentes comportamentais (como o ensaio comportamental), cognitivos (como a reestruturação cognitiva) e fisiológicos (como o relaxamento) típicos dos déficits em habilidades sociais.

Este tipo de intervenção almeja minimizar consequências de déficits acentuados em habilidades sociais já instalados, como é o caso dos participantes da pesquisa que possuem uma doença crônica. Considera-se, portanto, que programas de desenvolvimento de habilidades sociais sejam uma ferramenta valiosa na atuação em saúde, sendo útil para minimizar fatores de risco e incrementar fatores de proteção ao desenvolvimento humano, tratar problemas já instalados passíveis de remissão e reduzir o impacto de déficits graves em habilidades sociais em pessoas portadoras de condições crônicas (Murta, 2005).

Embora não tenha sido constatada diferença dos grupos nas escalas de IHS e a média e mediana do grupo de rim parecesse ser bem maior, há alta variabilidade nas respostas, com desvios-padrão elevados. Isso significa que essa diferença na pontuação pode ser fruto do acaso. Com um $\mathrm{N}$ maior 
talvez fosse possível detectar alguma diferença, mas a distribuição dos dados não produziu diferenças significativas.

Em relação ao repertório específico de Coping foi observado que o Fator Instrumental teve maior frequência, portanto, as estratégias são focadas no problema. Entende-se com esses resultados que os participantes possuem recursos para buscar informações com a equipe interdisciplinar, com fontes médicas e informações sob diferentes aspectos associados ao tratamento. Essas informações auxiliam a manter a esperança e o otimismo frente às dificuldades encontradas após a cirurgia, como a adesão ao tratamento e efeitos colaterais da medicação, identificados como fatores de estresse relacionados à espera do transplante.

O segundo fator mais utilizado na Escala de Coping foi o Fator Distração, como recurso de enfrentamento do problema de saúde dos participantes à espera do transplante. Estes comportamentos concentram-se essencialmente em recursos que o indivíduo consiga pensar em outros assuntos (mais agradáveis), dedicar-se a atividades que não tenham relação com o problema, ou ainda procurar apoio social.

O fato de buscarem suporte social indica tendência a utilizar enfrentamento externo para lidar com as dificuldades. A necessidade de consultas e hospitalizações frequentes e a alta chance de rejeição aguda levam o paciente a procurar ajuda de pessoas próximas. Esta forma de enfrentamento tem algumas vantagens, pois, outras pessoas podem auxiliar o doente e outros pacientes, em situação semelhante, e frequentemente atuar como fonte importante de suporte social, muitas vezes utilizada formalmente pelo sistema de saúde, como grupos de sala de espera para informação e até mesmo grupos psicoterapêuticos (Ravagnani et al., 2007).

O Fator Distração também apresenta comportamentos desejáveis e indesejáveis. O conjunto de comportamentos de Coping pode ser entendido como fuga/esquiva, já que os aversivos (doença, tratamento, por exemplo) estão presentes e o repertório de Coping pode diminuir ou excluir esses aversivos. Porém, alguns comportamentos como, falha em identificar sintomas importantes, protelar a busca de ajuda, evitar consultas e exames e não tomar a medicação corretamente, também tem uma função de fuga/esquiva, mas são comportamentos pouco desejáveis para os tratamentos de doenças crônicas. Segundo Del Prette e Del Prette (2010) os indivíduos consideram um repertório socialmente competente quando estes trazem consequências de curto prazo, ou seja, quando as estratégias de Coping minimizam os aversivos, porém não os elimina. As consequências de médio e longo prazo incluem manutenção de alguns comportamentos para a eliminação de aversivos, que garanta não apenas qualidade ao sujeito, mas manutenção ou melhoria na qualidade da relação deste com o seu meio, garantindo um equilíbrio entre as trocas positivas de reforço.

Os comportamentos de fuga/esquiva também fazem parte do Fator Paliativo. O Coping Paliativo foi o terceiro fator de maior frequência observado no estudo e correlaciona-se negativamente com a qualidade de vida, pois envolve um conjunto de comportamentos que avalia acontecimentos desagradáveis, centrando-se em sintomas individuais e tentativas de autocuidado, o que leva o indivíduo a um certo isolamento social (Ruivo, 1999).

O Fator Emoção/Preocupação foi o que apresentou menor frequência e esse fato pode ser considerado positivo, já que é geralmente utilizado quando as pessoas acreditam que podem fazer pouco para alterar a situação, ou quando acreditam que seus recursos são insuficientes para suportar sua atual condição de saúde. No caso das correlações de Coping e qualidade de vida, de acordo com Ruivo (1999), verificou-se que quanto maior o Coping Emocional/Preocupação, menor é a qualidade de vida. Segundo Lazarus e Folkman (1984) o Coping orientado pelas emoções/preocupações ocorre imediatamente após os acontecimentos do evento estressor, mas deve ser substituído por estratégias orientadas para o problema, como o Coping Instrumental e de Distração em que a pessoa se dirige a outros assuntos e tenta saber mais sobre o problema e isso garante maior qualidade de vida e diminuição de estresse.

Porém, mais importante do que centrar o Coping em um aspecto, é utilizá-lo de maneira conjunta, embora haja possibilidade de um prevalecer sobre o outro em fases específicas da doença e de acordo com as necessidades (Ravagnani et al., 2007). Na amostra estudada, os participantes, de 
uma maneira geral, apresentaram escores relativamente bons de Coping. Pensando em uma escala de avaliação em que a média máxima seja cinco, os participantes candidatos a transplante renal tiveram média 4,00 e os de fígado 3,71. Embora estatisticamente não haja muita diferença entre esses dois tipos de transplante, observa-se uma sutil diferença nas estratégias dos pacientes à espera do transplante renal e fígado.

Por suposição pode-se pensar que algumas variáveis poderiam interferir no repertório de Coping, como, por exemplo, o número de pessoas à espera do transplante e a quantidade de órgãos disponíveis que, consequentemente, altera o número de transplantes realizados. Segundo a Associação Brasileira de Transplante de Órgãos (2014), no ano de 2014 foram realizados 5.639 transplantes renais e 1.755 transplantes de fígado. Portanto, os pacientes renais crônicos apresentam maior perspectiva de transplante e permanecem menos tempo na condição de doentes que os paciente à espera de um fígado. Com isso, os impactos da doença e o Coping podem variar e apresentar frequências diferentes, conforme observa-se na presente pesquisa.

Outro fator que pode influenciar é a perspectiva de melhora após a realização do transplante. Segundo Gimenes (1997), o risco de morte pode interferir no Coping, pois, os pacientes possuem exemplos que a superação da fase crônica da doença e a realização do transplante trará qualidade futura de vida e diminuem a chance de morte. No caso dos dois tipos de transplantes analisados aqui, os resultados, segundo o Instituto de Pesquisa Econômica Aplicada (2013), mostram que os transplantes renais podem ser considerados como bons, com sobrevida em quatro anos do paciente (95\% e $88 \%$ ) de órgãos vindos de pessoas vivas e mortas, respectivamente. No caso dos transplantes de fígado, as estatísticas são menores, tendo chance de sobrevida de $70 \%$ com órgãos de pessoas vivas e $68 \%$ de pessoas mortas.

Por fim, os dados fornecem alguns subsídios para o desenvolvimento de futuras pesquisas que poderiam explorar melhor as variáveis que controlam a emissão de comportamentos de Coping e o repertório de habilidades sociais. Assim como medir o impacto do treino de habilidades sociais antes e depois da intervenção e a avaliação do repertório de Coping, com o objetivo de auxiliar os candidatos ao transplante aderirem melhor ao tratamento, ao comparecimento às consultas, cumprimento de dieta ou procedimentos médicos, já que esse conjunto de comportamentos pode ser fundamental para o enfrentamento de novas situações, no caso da doença crônica hepática e renal, e o enfrentamento da condição de espera do transplante.

\section{Referências}

Associação Brasileira de Transplante de Órgãos (2014). Dimensionamento dos transplantes no Brasil e em cada estado (2007-2014). Registro Brasileiro de Transplantes.

Bandeira, M., Costa, M. N., Del Prette, Z. A. P., Del Prette, A. \& Gerk-Carneiro, E. (2000). Qualidades psicométricas do Inventário de Habilidades Sociais (IHS): estudo sobre a estabilidade temporal e a validade concomitante. Estudos de Psicologia, 5(2), 401-419.

Bolsoni-Silva, A. T. \& Carrara, K. (2010). Habilidades sociais e análise do comportamento: compatibilidades e dissensões conceitual-metodológicas. Psicologia em Revista, 16(2), 330-350.

Caballo, V. E. (2006). Manual de Avaliação e Treinamento das Habilidades Sociais. $1^{\text {a }}$ reimpressão. São Paulo: Santos.

Del Prette, Z. A. P. \& Del Prette, A. (2001). Inventário de Habilidades Sociais (IHS-DelPrette): Manual de aplicação, apuração e interpretação. São Paulo: Casa do Psicólogo.

Del Prette, Z. A. P. \& Del Prette A. (2005). Psicologia das habilidades sociais na infância: teoria e prática. Petrópolis: Editora Vozes.

Del Prette, Z. A. P. \& Del Prette, A. (2010). Social skills and behavior analysis: Historical proximity and new issues. Revista Perspectivas, 1(2), 004-015.

Domingos, N. A M., Lipp, M. E. N. \& Miyazaki M. C. O. S. (2012). Stress, ansiedade, depressão e estratégias de enfrentamento em candidatos a transplante de fígado: intervenção psicológica. Revista de Motivación y Emoción, 1, 40-46.

Endler, N. S. Parker, J. D. A., \& Summerfeldt, L. J. (1998). Coping with health problems: developing a reliable and valid multidimensional measure. Psychological Assessment, 10, 195-205. 
Folkman, S. \& Lazurus, R. S. (1985). If it changes it must be a process: study of emotion and coping during three stages of a college examination. Journal of Personality and Social Psychology, 48(1), 150-170.

Gimenes, M. G. G. (1997). A teoria do enfrentamento e suas implicações para sucessos e insucessos em psiconcologia. Em: M. G. G. Gimenes \& M. H. Fávero (Orgs.), A mulher e o câncer (pp.111-147). Campinas: Editorial Psy.

Hymovich, D. P. \& Hagopian, G. A. (1992). Chronic illness in children and adults: a psychosocial approach. Philadelphia: W. B. Saunders.

Instituto de Pesquisa Econômica Aplicada (2013). Disponível em: http://www.ipea.gov.br/portal/. (Acessado em: 30/06/2015).

Lazarus, R. S. \& Folkman, S. (1984). Stress, appraisal, and coping. New York: Springer Publishing Company.

McCrae, R. R. (1984). Situational determinants of coping responses: loss, threat, and challenge. Journal of Personality and Social Psychology, 46(4), 919-928.

Miyazaki, M. C. O. S., Domingos, N. A. M., Valério, N. I., Souza, E. F. \& Silva, R. T. M. A. (2005). Tratamento da hepatite C: sintomas psicológicos e estratégias de enfrentamento. Revista Brasileira de Terapias Cognitivas, 1(1), 119-128.

Moss, R. H. \& Billings, A. (1982). Conceptualizing and measuring coping resources and process. Em: L. Goldberger \& S. Breznitz (Orgs..), Handbook of stress: theorical e clinical aspects (pp. 212-230). New York, Free Press.

Murta, S. H. (2005). Aplicações do treinamento em habilidades sociais: Análise da produção nacional. Psicologia: Reflexão e Crítica, 18(2), 283-291.

Pinto, F. N. F. R. \& Barham, E. J. (2014). Habilidades sociais e estratégias de enfrentamento de estresse: relação com indicadores de bem-estar psicológico em cuidadores de idosos de alta dependência. Revista Brasileira de Geriatria e Gerontologia, 17(3), 525-539.

Ramos, F. P., Enumo, S. R. F. \& Paula, K. M. P. (2015). Teoria Motivacional do Coping: uma proposta desenvolvimentista de análise do enfrentamento do estresse. Estudos de Psicologia, 32(2), 269-279.
Ravagnani, L. M. B., Domingos, N. A. M. \& Miyazaki, M. C. O. S. (2007). Qualidade de vida e estratégias de enfrentamento em pacientes submetidos a transplante renal. Estudos de Psicologia, 12(2), 177-184.

Ruivo, M. A. (1999). Stress, Coping e qualidade de vida em indivíduos transplantados renais (Dissertação de mestrado). Instituto Superior de Psicologia Aplicada, Lisboa.

Savóia, M. G., Santana, P. R. \& Mejias, N. P. (1996). Adaptação do inventário de Estratégias de Coping ${ }^{1}$ de Folkman e Lazarus para o português. Psicologia USP, 7(1/2), 183-201.

Simmons, R. G., Marine, S. K. \& Simmons, R. L. (1987). Gift of life: the effect of organ transplantation on individual, family, and societal dynamics. New Brunswick and Oxford: Transaction Books.

Stone, A. A. \& Neale, J. M. (1984). New measure of daily coping: development and preliminary results. Journal of Personality and Social Psychology, 46(4), 892-906.

Telles-Correia, D., Mega, I., Barbosa, A., Barroso, E. \& Monteiro, E. (2008). Coping nos doentes transplantados. Acta Médica Portuguesa, 21, 141-148.

\section{Informações do Artigo}

Histórico do artigo:

Histórico do artigo:

Submetido em: 21/11/2016

Primeira decisão editorial: 24/05/2017

Aceito em: 23/10/2017

Editor: Nicodemos B. Borges 